\title{
U.S. National Healthcare Expenditures: Demonstration and Explanation of Cubic Growth Dynamics
}

\author{
Jack E. Riggs ${ }^{1}$, Jeffrey C. Hobbs ${ }^{2}$, Gerald R. Hobbs ${ }^{3}$, Todd H. Riggs ${ }^{4}$ \\ ${ }^{1}$ Department of Neurology, West Virginia University, Morgantown, USA \\ ${ }^{2}$ Department of Finance, Banking and Insurance, Appalachian State University, Boone, USA \\ ${ }^{3}$ Department of Statistics, West Virginia University, Morgantown, USA \\ ${ }^{4} 1^{\text {st }}$ Aviation Training Brigade, United States Army, Fort Rucker, USA \\ E-mail:jriggs@wvu.edu,hobbsjc@appstate.edu,ghobbs@stat.wvu.edu,todd.riggs@us.army.mil \\ Received August 7, 2011; revised September 23, 2011; accepted September 30, 2011
}

\begin{abstract}
U.S. national healthcare expenditures (NHE) increased from under 28 billion dollars in 1960 to over 1.35 trillion dollars in 2000. This enormous growth threatens the sustainability of the provision of healthcare. By definition, in any year, current NHE must equal population times consumer price index (CPI) times per capita CPI-adjusted constant dollar healthcare expenditures. Linear relationships were observed over time with total population $\left(r^{2}>0.99\right)$, with CPI $\left(r^{2}>0.96\right)$, and with per capita CPI-adjusted dollar healthcare expenditures $\left(r^{2}>0.98\right)$. The finding that those three factors were well described by linear equations suggests that NHE growth should display cubic dynamics over time. NHE from 1960 through 2000 did display cubic growth dynamics $\left(\mathrm{r}^{2}>0.99\right)$. Moreover, actual NHE from 1960 through official U.S. government NHE projections in 2019 also displayed cubic growth dynamics $\left(r^{2}>0.99\right)$. This model explains why U.S. NHE has displayed cubic growth dynamics and suggests that U.S. NHE will continue to display cubic growth dynamics as long as increases in population, CPI, and per capita CPI-adjusted constant dollar healthcare expenditures continue to increase reasonably linearly over time.
\end{abstract}

Keywords: Consumer Price Index, Cubic Dynamics, Economic Modeling, National Healthcare Expenditures, Per Capita Healthcare Expenditures, Population, United States

\section{Introduction}

Rising national healthcare expenditures (NHE) are consistently in the U.S. national political and economic spotlight [1-4]. NHE increased nearly 50 -fold in the U.S. between 1960 and 2000, from under 28 billion dollars to over 1.35 trillion dollars per year (Table 1). This enormous growth in NHE threatens the sustainability of healthcare for many Americans since employers cannot afford the large ongoing increases in healthcare insurance premiums for their employees, healthcare insurance companies continuously seek to control their risk by excluding high risk patients and restricting covered benefits, governments cannot afford to provide unlimited benefits for its citizens by shifting the costs to future taxpayers, and very few individuals can afford to pay for their own healthcare should a significant injury or illness occur. This enormous growth in healthcare expenditures seriously undermines the sustainability of national discre- tionary spending. A June 2010 Congressional Budget Office report stated, "Because health care costs will account for a significant share of the federal budget under current law, and the growth of those costs is a major contributor to the long-term fiscal pressures facing the country, policy options to restrain the growth of federal spending on health care will continue to attract considerable interest." (http://www.cbo.gov/ftpdocs/115xx/doc 11579/06-30-LTBO.pdf).

Despite the impact and importance of rising NHE, very little regarding the dynamics of this enormously increasing and very important sector of the U.S. economy has been described [5]. By definition, in any given year, current NHE must equal population times consumer price index (CPI) times per capita CPI-adjusted constant dollar healthcare expenditures. Trends in these three factors must, therefore, influence total NHE. Trends in population, consumer price index, and per capita CPI-adjusted healthcare expenditures were explored to 
determine if they might suggest or reveal a model explaining the underlying growth dynamics of U.S. NHE.

\section{Method \& Model}

\subsection{Data Sources}

Three public and readily available sources of data for the years 1960 through 2000 were used in this analysis. Official estimates of the total U.S. population for those years (Table 1) were obtained from the U.S. Census Bureau (www.census.gov). Official estimates of the U.S. consumer price index (CPI) for those years (Table 1) were obtained from the U.S. Department of Labor, Bureau of Labor Statistics (www.bls.gov). Official estimates of total U.S. NHE in current dollars for those years (Table 1) were obtained from the U.S. Department of Health and Human Services, Centers for Medicare \& Medicaid Services (www.cms.hhs.gov). Dividing the annual total NHE by that year's CPI gives the annual NHE in CPI-adjusted dollars. Dividing the annual NHE in CPI-adjusted dollars by the corresponding annual population gives the annual per capita CPI-adjusted healthcare expenditures. The relationship of annual population, CPI, and per capita CPI-adjusted healthcare expenditures over time, between 1960 and 2000, was examined.

\subsection{Model}

Figure 1 illustrates the relationship between total U.S. population and year. As shown, there is a strong linear relationship between total U.S. population and year. Linear regression between total population and year yielded the following equation:

$$
\mathrm{POP}_{\mathrm{x}}=2293408.2 \mathrm{X}+181774463
$$

where $\mathrm{POP}_{\mathrm{x}}$ is the total U.S. population in year $\mathrm{X}$, and $\mathrm{X}$ is the year, which varied from 0 for year 1960 to 40 for year 2000. The $\mathrm{r}^{2}$ value for this linear regression was $>$ 0.99. Thus, the total U.S. population increased by approximately 2293408 individuals per year between the years 1960 and 2000. The least-squares estimate of the parameters in the regression equation:

$$
\mathrm{POP}_{\mathrm{x}}=\mathrm{aX}+\mathrm{A}
$$

is therefore, a is 2293408.2, and A is 181774463.

Figure 2 illustrates the relationship between CPI and year. As shown, there is a reasonably linear relationship between CPI and year. The linear regression between CPI and year yielded the following equation:

$$
\mathrm{CPI}_{\mathrm{x}}=0.040218641 \mathrm{X}+0.0643875
$$

where $\mathrm{CPI}_{\mathrm{x}}$ is the consumer price index in year $\mathrm{X}$, and $\mathrm{X}$ is the year, which varied from 0 for year 1960 to 40 for year 2000. The $r^{2}$ value for this linear regression was $>$ 0.96 . Thus, the CPI increased by approximately 0.0402 per year between the years 1960 and 2000. Since the numbers in Equation 3 are constants, the following equation will be used:

$$
\mathrm{CPI}_{\mathrm{x}}=\mathrm{bX}+\mathrm{B}
$$

where $\mathrm{b}$ is 0.040218641 , and $\mathrm{B}$ is 0.0643875 .

Figure 3 illustrates the relationship between per capita CPI-adjusted healthcare expenditures and year. As shown, there is a near linear relationship between per capita CPI-adjusted healthcare expenditures and year. Linear regression between per capita CPI-adjusted healthcare expenditures and year yielded the following equation:

$$
\text { PCNHE }_{\mathrm{x}}=60.181652 \mathrm{X}+335.2974
$$

where $\mathrm{PCNHE}_{\mathrm{x}}$ is the per capita CPI-adjusted healthcare expenditures in year $\mathrm{X}$, and $\mathrm{X}$ is the year, which varied from 0 for year 1960 to 40 for year 2000. The $r^{2}$ value for this linear regression was $>0.98$. Thus, per capita

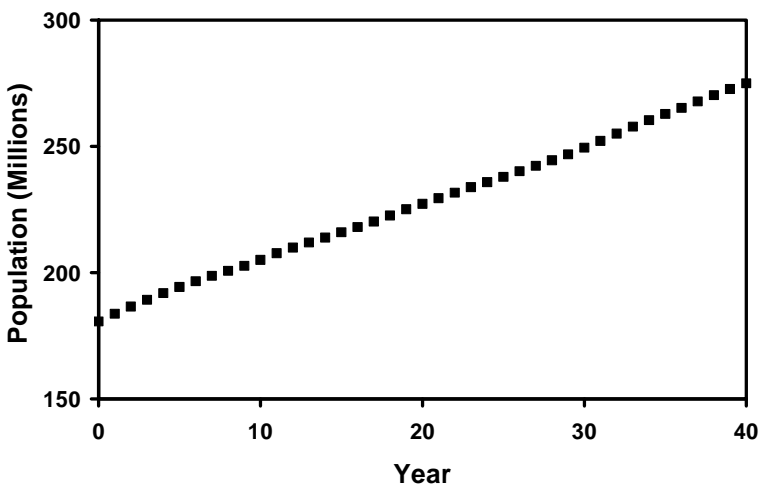

Figure 1. Total U.S. population for the years 1960 (year 0) through 2000 (year 40) is displayed. The $r^{2}$ value for the linear regression performed on this data was $>0.99$.

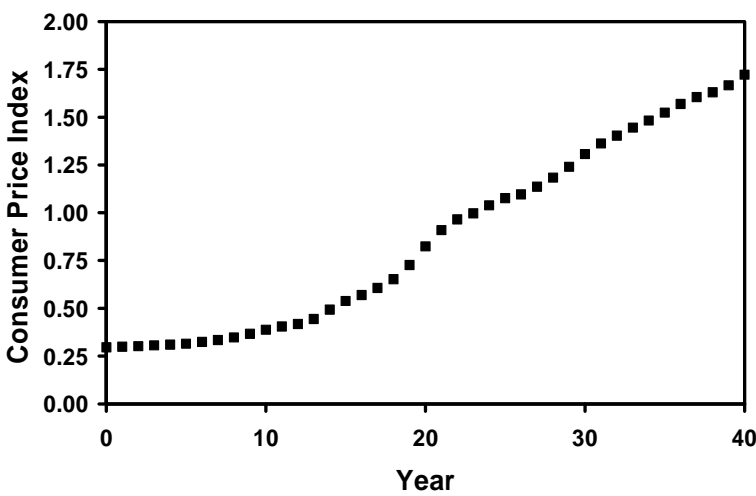

Figure 2. The consumer price index (CPI) for the years 1960 (year 0) through 2000 (year 40) is displayed. The r2 value for the linear regression performed on this data was $>$ 0.96 . 
Table 1. United States national healthcare expenditures (NHE) in millions of dollars, population, consumer price index (CPI), and cubic modeled NHE in millions of dollars for the years 1960-2000.

\begin{tabular}{|c|c|c|c|c|}
\hline Year & NHE & Population & CPI & Modeled NHE \\
\hline 1960 & 27,534 & $180,671,158$ & 0.296 & 3924 \\
\hline 1961 & 29,370 & $183,691,481$ & 0.299 & 7615 \\
\hline 1962 & 32,053 & $186,537,737$ & 0.302 & 12,298 \\
\hline 1963 & 34,910 & $189,241,798$ & 0.306 & 18,008 \\
\hline 1964 & 38,694 & $191,888,791$ & 0.310 & 24,777 \\
\hline 1965 & 42,173 & $194,302,963$ & 0.315 & 32,639 \\
\hline 1966 & 46,430 & $196,560,338$ & 0.324 & 41,626 \\
\hline 1967 & 52,062 & $198,712,056$ & 0.334 & 51,774 \\
\hline 1968 & 59,012 & $200,706,052$ & 0.348 & 63,114 \\
\hline 1969 & 66,396 & $202,676,946$ & 0.367 & 75,680 \\
\hline 1970 & 74,894 & $205,052,174$ & 0.388 & 89,505 \\
\hline 1971 & 83,265 & $207,660,677$ & 0.405 & 104,623 \\
\hline 1972 & 92,974 & $209,896,021$ & 0.418 & 121,067 \\
\hline 1973 & 103,034 & $211,908,788$ & 0.444 & 138,870 \\
\hline 1974 & 116,809 & $213,853,928$ & 0.493 & 158,066 \\
\hline 1975 & 133,124 & 215,973,199 & 0.538 & 178,688 \\
\hline 1976 & 152,478 & $218,035,164$ & 0.569 & 200,769 \\
\hline 1977 & 172,826 & $220,239,425$ & 0.606 & 224,342 \\
\hline 1978 & 194,126 & $222,584,545$ & 0.652 & 249,441 \\
\hline 1979 & 219,940 & $225,055,487$ & 0.726 & 276,099 \\
\hline 1980 & 253,373 & $227,224,681$ & 0.824 & 304,349 \\
\hline 1981 & 293,592 & $229,465,714$ & 0.909 & 334,226 \\
\hline 1982 & 330,743 & $231,664,458$ & 0.965 & 365,761 \\
\hline 1983 & 364,676 & 233,791,994 & 0.996 & 398,988 \\
\hline 1984 & 401,599 & $235,824,902$ & 1.039 & 433,941 \\
\hline 1985 & 430,284 & $237,923,795$ & 1.076 & 470,653 \\
\hline 1986 & 471,265 & $240,132,887$ & 1.096 & 509,158 \\
\hline 1987 & 512,973 & $242,288,918$ & 1.136 & 549,487 \\
\hline 1988 & 574,043 & $244,498,982$ & 1.183 & 591,676 \\
\hline 1989 & 638,794 & $246,819,230$ & 1.240 & 635,757 \\
\hline 1990 & 714,127 & $249,464,396$ & 1.307 & 681,763 \\
\hline 1991 & 781,608 & $252,153,092$ & 1.362 & 729,728 \\
\hline 1992 & 849,039 & $255,029,699$ & 1.403 & 77,968 \\
\hline 1993 & 912,485 & $257,783,000$ & 1.445 & 831,667 \\
\hline 1994 & 962,061 & $260,327,021$ & 1.482 & 885,708 \\
\hline 1995 & $1,016,271$ & $262,803,276$ & 1.524 & 941,841 \\
\hline 1996 & $1,068,526$ & 265228572 & 1.569 & $1,000,100$ \\
\hline 1997 & $1,124,915$ & $267,784,000$ & 1.605 & $1,060,517$ \\
\hline 1998 & $1,190,059$ & $270,248,003$ & 1.630 & $1,123,125$ \\
\hline 1999 & $1,265,158$ & $272,690,813$ & 1.666 & $1,187,959$ \\
\hline 2000 & 1,353,187 & $274,951,554$ & 1.722 & $1,255,052$ \\
\hline
\end{tabular}




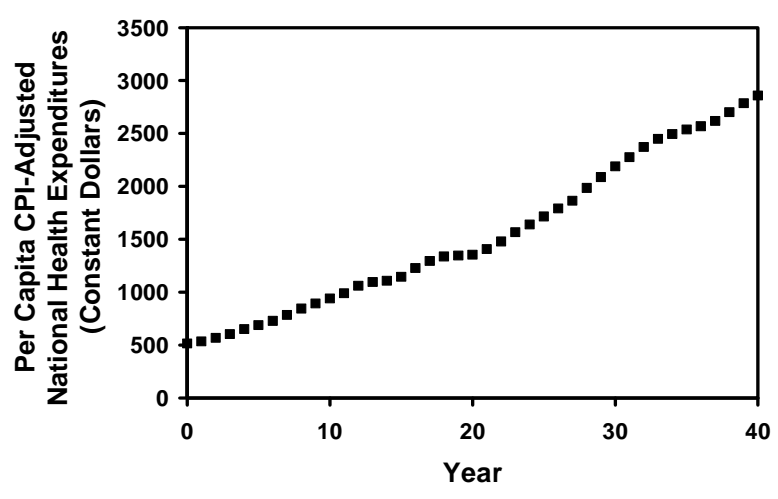

Figure 3. Per capita CPI-adjusted constant dollar U.S. healthcare expenditures for the years 1960 (year 0) through 2000 (year 40) is displayed. The $\mathbf{r}^{2}$ value for the linear regression performed on this data was $>\mathbf{0 . 9 8}$.

CPI-adjusted healthcare expenditures increased by approximately $\$ 60.18$ per year between the years 1960 and 2000. Since the numbers in Equation (5) are constants, the following equation can be used:

$$
\mathrm{PCNHE}_{\mathrm{x}}=\mathrm{CX}+\mathrm{C}
$$

where $\mathrm{c}$ is 60.181652 , and $\mathrm{C}$ is 335.2974 .

For any given year, the following relationship is valid:

$$
\mathrm{NHE}_{\mathrm{x}}=\left(\mathrm{POP}_{\mathrm{x}}\right) \times\left(\mathrm{CPI}_{\mathrm{x}}\right) \times\left(\mathrm{PCNHE}_{\mathrm{x}}\right)
$$

where $\mathrm{NHE}_{\mathrm{x}}$ is national healthcare expenditures in current dollars in year $\mathrm{X}, \mathrm{POP}_{\mathrm{x}}$ is the total U.S. population in year $\mathrm{X}, \mathrm{CPI}_{\mathrm{X}}$ is the consumer price index in year $\mathrm{X}$, and $\mathrm{PCNHE}_{\mathrm{x}}$ is the per capita CPI-adjusted healthcare expenditures in year $\mathrm{X}$. Substituting the linear regression derived equations for $\mathrm{POP}_{\mathrm{x}}, \mathrm{CPI}_{\mathrm{x}}$, and $\mathrm{PCNHE}_{\mathrm{x}}$ into Equation (7) yields:

$$
\mathrm{NHE}_{\mathrm{x}}=(\mathrm{aX}+\mathrm{A}) \times(\mathrm{bX}+\mathrm{B}) \times(\mathrm{cX}+\mathrm{C})
$$

Multiplying out the terms in Equation (8) yields the following equation:

$$
\begin{aligned}
\mathrm{NHE}_{\mathrm{x}}= & \mathrm{abcX^{3 }}+(\mathrm{Abc}+\mathrm{aBc}+\mathrm{abC}) \mathrm{X}^{2} \\
& +(\mathrm{ABc}+\mathrm{AbC}+\mathrm{aBC}) \mathrm{X}+\mathrm{ABC}
\end{aligned}
$$

Equation (9) suggests that NHE should be described by a cubic function over time as long as POP, CPI, and PCNHE are reasonably described by linear equations. Accordingly, a cubic polynomial fit of national healthcare expenditures (Table 1) over time was performed. That analysis demonstrated that NHE between 1960 and 2000 conformed to a cubic function, and the $r^{2}$ value of that fit was $>0.99$.

Equation (7) was used to model or predict annual values of NHE for each year from 1960 to 2000 by calculating the product of the derived Equations (1), (3), and (5). These values are also shown in Table 1. Figure 4 displays a plot of actual and modeled NHE from 1960 to
2000. This cubic model of NHE growth, based on the product of the three derived linear equations from 1960 to 2000 data, correlated very well with actual NHE from 1960 to 2000, with an $r^{2}$ value of that fit $>0.99$.

Since this model predicts that NHE growth should display cubic dynamics, combined actual (1960 to 2008) and official U.S. government predictions (2009 to 2019) of NHE (www.cms.hhs.gov) were plotted in Figure 5. A cubic polynomial fit of national healthcare expenditures over that time period was performed. That analysis demonstrated that actual and projected NHE between 1960 and 2019 also conformed to a cubic function, and the $\mathrm{r}^{2}$ value of that fit was $>0.99$.

\section{Discussion}

A model of NHE based on the fact that in any year, current NHE must equal population times CPI times per capita CPI-adjusted constant dollar healthcare expenditures (Equation 7) was developed and analyzed. Equation 7 is a truism; that is, Equation 7 can be algebraically

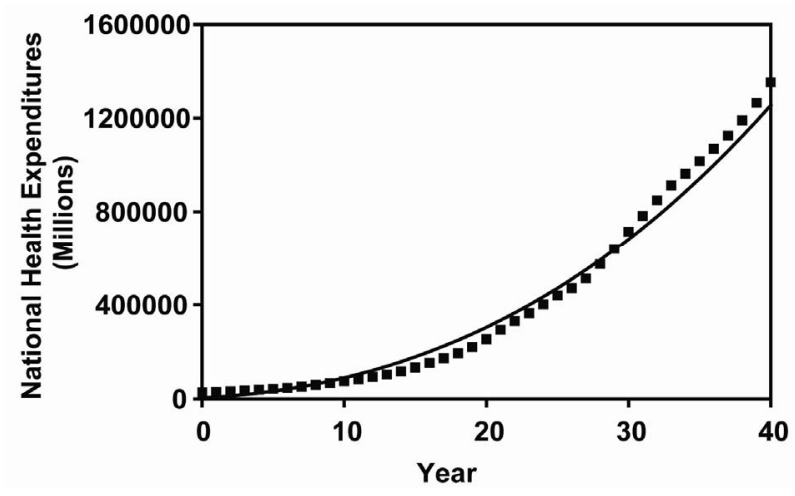

Figure 4. Actual (squares) and modeled (solid line) national health expenditures (in current millions of dollars) for year 0 (1960) through year 40 (2000).

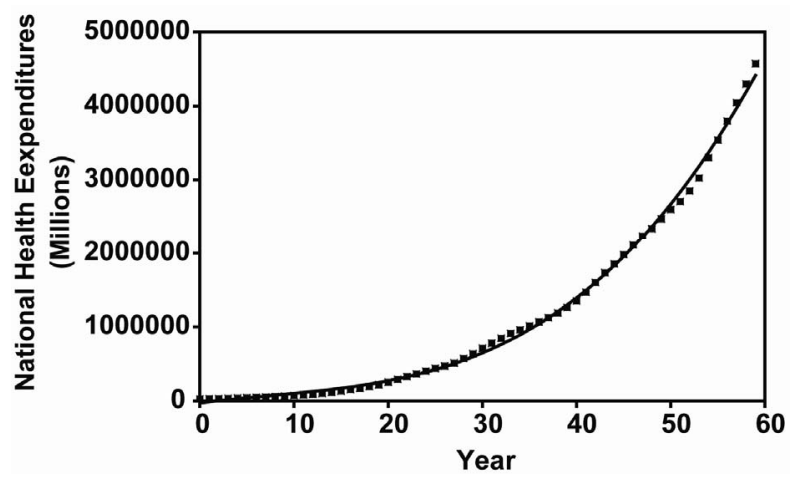

Figure 5. Actual (1960 to 2008) and projected (2009 to 2019) (squares) and best cubic fit (solid line) national health expenditures (in current millions of dollars) for year 0 (1960) through year 59 (2019). 
simplified to state that for any given year, NHE must equal NHE. However, the point of this model was to separate NHE into three distinct components; population, CPI, and per capita CPI-adjusted constant dollar healthcare expenditures. There is no a priori reason why each of these three components should increase linearly over time as was demonstrated in this analysis. Since population, CPI, and per capita CPI-adjusted constant dollar healthcare expenditures did increase reasonably linearly over time between 1960 and 2000, this model suggested that NHE growth should display cubic growth dynamics. Indeed, NHE growth did display cubic dynamics from 1960 to 2000. Moreover, actual and projected NHE growth from 1960 to 2019 also displayed cubic dynamics. This analysis also suggests that future U.S. NHE growth will remain cubic as long as increases in population, CPI, and per capita CPI-adjusted constant dollar healthcare expenditures remain reasonably linear over time. Cubic growth is important to distinguish from exponential growth.

Although explaining the cubic growth of U.S. NHE, this model does not accurately predict future NHE. We performed multiple analyses to determine whether knowing that NHE increases cubically over time would allow accurate prediction of future NHE. For example, determining the cubic equation that best fit NHE's from 1960 to 1980 does not allow an accurate prediction of NHE in 1990. The reason for this failure to accurately predict is that each new data point of population, CPI, and per capita CPI-adjusted constant dollar healthcare expenditures does alter the corresponding linear equation slightly. The slightly altered linear equations will still accommodate all prior data points and produce a wellfitted cubic function describing their product of previous years' NHE. However, when the three slightly altered linear equations are multiplied together, their product will not accurately predict future NHE due to the compounding of errors. This dichotomy of hypotheses or models, those that accommodate and explain past data while failing to predict future data, is well-recognized in science [6-10]. A classic example of this dichotomy is Darwin's theory of evolution by natural selection. Darwin's theory explains the appearance and extinction of past species, but can not predict the future course of evolution [8]. Although unable to predict future NHE, appreciation of the cubic dynamics describing NHE may provide healthcare policy makers an improved framework upon which to assess and monitor the impact of healthcare policy changes.

Orszag and Ellis [11] suggested that "our country's financial health will in fact be determined by the growth rate of per capita health care costs." In this model of U.S. NHE growth used to predict cubic dynamics, one might assume that population growth and CPI growth were relatively outside the influence of the U.S. healthcare system. The remaining factor, constant dollar per capita healthcare expenses, is consistent with the assertion made by Orszag and Ellis [11]. While inflation adjusted total per capita healthcare expenses have increased over time [12], some public sector (Medicare) per capita healthcare expenses have been claimed to have actually declined [13]. Nevertheless, the impact of escalating health care spending on the U.S. economy will continue to be debated [14-16].

\section{Conclusions}

Rising healthcare costs impacts all sectors of the U.S. economy and is eroding the sustainability of U.S federal discretionary spending. Indeed, increasing healthcare costs are not exclusively a U.S. economic problem; escalating healthcare costs are a global problem. While this analysis does not attempt to show how to decrease the rate of healthcare cost growth, it does suggest that inflation-adjusted per capita healthcare costs is perhaps the best measure to track and monitor NHE growth. Moreover, this analysis suggests that healthcare policy changes that merely shift the cost of healthcare expenses will have little impact on NHE growth.

\section{References}

[1] T. Bodenheimer, "High and Rising Health Care Costs. Part 1: Seeking an Explanation," Annals of Internal Medicine, Vol. 142, 2005, pp. 847-854.

[2] T. Bodenheimer, "High and Rising Health Care Costs. Part 2: Technologic Innovation,” Annals of Internal Medicine, Vol. 142, 2005, pp. 932-937.

[3] T. Bodenheimer, "High and Rising Health Care Costs. Part 3: The Role of Health Care Providers,” Annals of Internal Medicine, Vol. 142, 2005, pp. 996-1002.

[4] T. Bodenheimer, "High and Rising Health Care Costs. Part 4: Can Costs be Controlled While Preserving Quality?” Annals of Internal Medicine, Vol. 143, 2005, pp. 26-31.

[5] E. French and J. B. Jones, "On the Distribution and Dynamics of Health Care Costs," Journal of Applied Economics, Vol. 19, No. 6, 2004, pp. 705-721. doi:10.1002/jae.790

[6] C. G. Hempel and P. Oppenheim, "Studies in the Logic of Explanation,” Philosophy of Science, Vol. 15, No. 2, 1948, pp. 135-175. doi:10.1086/286983

[7] N. Rescher, "On Prediction and Explanation,” British Journal for the Philosophy of Science, Vol. 8, No. 32, 1958, pp. 281-290. doi:10.1093/bjps/VIII.32.281

[8] M. Scriven, "Explanation and Prediction in Evolutionary Theory,” Science, Vol. 130, No. 3374, 1959, pp. 477-482. 


\section{doi:10.1126/science.130.3374.477}

[9] J. F. Hanna, "Explanation, Prediction, Description, and Information Theory," Synthese, Vol. 20, No. 3, 1969, pp. 308-334. doi:10.1007/BF00413732

[10] D. Dharmapala and M. McAleer, "Prediction and Accommodation in Econometric Modeling," Environmetrics, Vol. 6, No. 5, 1995, pp. 551-556. doi:10.1002/env.3170060522

[11] P. R. Orszag and P. Ellis, "The Challenge of Rising Health Care Costs-A View from the Congressional Budget Office," New England Journal of Medicine, Vol. 357, No. 18, 2007, pp.1793-1795. doi:10.1056/NEJMp078190

[12] D. E. Altman and L. Levitt, “The Sad History of Health Care Cost Containment Astold in One Chart," Health Affairs (Millwood), Suppl Web Exclusives W83-4, 2002. http://content.healthaffairs.org/content/early/2002/02/23/ hlthaff.w2.83.full.pdf+html

[13] T. Bodenheimer, "The Not-So-Sad History of Medicare Cost Containment as Told in One Chart," Health Affairs
(Millwood), Suppl Web ExclusivesW88-90, 2002. http://content.healthaffairs.org/content/early/2002/02/23/ hlthaff.w2.88.full.pdf+html

[14] S. H. Altman, C. P. Tompkins, E. Eilat and M. P. V. Glavin, "Escalating Health Care Spending: Is It Desirable or Inevitable?” Health Affairs (Millwood), Suppl Web Exclusives W3-1-14, 2003.

http://content.healthaffairs.org/content/early/2003/01/08/hlthaff. w3.1.long

[15] M. V. Pauly, "Should We Be Worried about High Real Medical Spending Growth in the United States?” Health Affairs (Millwood), Suppl Web Exclusives W3-15-27, 2003. http://content.healthaffairs.org/content/early/2003/01/08/ hlthaff.w3.15.long

[16] H. J. Aaron, "Should Public Policy Seek to Control the Growth of Health Carespending?” Health Affairs (Millwood), Suppl Web Exclusives W3-28-36, 2003.

http://content.healthaffairs.org/content/early/2003/01/08/ hlthaff.w3.28.full.pdf+html 